\title{
Article
}

\section{Global Population Exposed to Extreme Events in the 150 Most Populated Cities of the World: Implications for Public Health}

\author{
Linze $\mathrm{Li}^{1,2}$, Chengsheng Jiang ${ }^{1}$, Raghu Murtugudde ${ }^{3}\left(\mathbb{D}\right.$, Xin-Zhong Liang ${ }^{3}{ }^{(0)}$ and Amir Sapkota ${ }^{1, *}$ \\ 1 Maryland Institute for Applied Environmental Health, University of Maryland School of Public Health, \\ College Park, MD 20742, USA; linzeli.whu@gmail.com (L.L.); cjiang89@umd.edu (C.J.) \\ 2 School of Remote Sensing and Information Engineering, Wuhan University, Wuhan 430079, China \\ 3 Earth System Science Interdisciplinary Center, University of Maryland, College Park, MD 20742, USA; \\ mahatma@umd.edu (R.M.); xliang@umd.edu (X.-Z.L.) \\ * Correspondence: amirsap@umd.edu; Tel.: +301-405-8716
}

check for updates

Citation: Li, L.; Jiang, C.;

Murtugudde, R.; Liang, X.-Z.;

Sapkota, A. Global Population

Exposed to Extreme Events in the 150

Most Populated Cities of the World:

Implications for Public Health. Int. J.

Environ. Res. Public Health 2021, 18,

1293. https://doi.org/10.3390/

ijerph18031293

Received: 23 December 2020

Accepted: 27 January 2021

Published: 1 February 2021

Publisher's Note: MDPI stays neutral with regard to jurisdictional claims in published maps and institutional affiliations.

Copyright: (c) 2021 by the authors. Licensee MDPI, Basel, Switzerland. This article is an open access article distributed under the terms and conditions of the Creative Commons Attribution (CC BY) license (https:// creativecommons.org/licenses/by/ $4.0 /)$.

\begin{abstract}
Climate change driven increases in the frequency of extreme heat events (EHE) and extreme precipitation events (EPE) are contributing to both infectious and non-infectious disease burden, particularly in urban city centers. While the share of urban populations continues to grow, a comprehensive assessment of populations impacted by these threats is lacking. Using data from weather stations, climate models, and urban population growth during 1980-2017, here, we show that the concurrent rise in the frequency of EHE, EPE, and urban populations has resulted in over $500 \%$ increases in individuals exposed to EHE and EPE in the 150 most populated cities of the world. Since most of the population increases over the next several decades are projected to take place in city centers within low- and middle-income countries, skillful early warnings and community specific response strategies are urgently needed to minimize public health impacts and associated costs to the global economy.
\end{abstract}

Keywords: climate change; extreme heat event; extreme precipitation event; megacities; urban area; urban heat island effect; global population

\section{Introduction}

Ongoing climate variability and change are increasing the frequency, duration, and intensity of extreme weather events across the globe [1,2]. Recent estimates suggest that these threats will cause approximately 250,000 deaths per year between 2030 and 2050 with direct damage costing $\$ 2-4$ billion per year [1,3]. Extreme heat events (EHE) and extreme precipitation events (EPE) are important attributes of climate variability and climate change that pose direct threats to public health across the globe. Previous studies have shown that exposure to extreme heat can increase the risk of mortality [4-8] and range of morbidity, including cardiopulmonary health outcomes [9-13]. Likewise, the increases in frequency of extreme precipitation events that are tied to warming climate can induce flooding, increase the risks of landslides, and degrade water quality [14,15]. Besides directly increasing the risk of death from drowning, EPE can also enhance the fecal-oral route of exposure to many pathogenic microorganisms and increase risk of food and waterborne illness [16-20]. In addition, EHE and EPE can also indirectly impact biodiversity, rainforest ecosystem deterioration, and food insecurity, which are all tied to human disease risks [1,2,21-24].

Increases in frequency of EHE and EPE may be higher in urban areas characterized by high population density and worsening air quality [25-27]. The increasing trend of EHE and EPE in these population centers is further exacerbated by the urban heat island effect that results from large areas of impervious land cover and low vegetation coverage [26,28-34]. This is particularly concerning to public health as the proportion of the global population residing in large urban centers continues to grow every year, with the most recent United Nation report suggesting that $68 \%$ of the world population will 
be living in such urban areas by 2050 [35]. As the world continues to urbanize, many megacities are facing challenges in meeting the needs of their growing urban populations, including housing, transportation, energy systems and other infrastructure, as well as employment and basic services such as education, health care and higher rates of urban poverty [36-38]. In addition, these urban centers are also notorious for disparities that exist with regards to income, food, and healthcare access [39-43]. The confluence of these factors make urban areas more vulnerable to threats posed by climate change related increases in extreme weather events [44]. Yet, there is a paucity of data regarding how frequency of EHE and EPE are being felt across the major population centers of the world. Currently, over one billion people reside in just 150 of the most populated cities. Most studies that have investigated the impacts of climate change on extreme events and resulting adverse human health impacts in urban population centers have originated primarily from developed countries with few exceptions [45-47]. This critical data gap limits the development of robust adaptation plans in cities within low- and middle-income countries where they are most urgently needed.

To address these issues, we characterized the frequency of EHE and EPE between 1980 and 2017 across the 150 most populated metropolitan locations of the world and estimated the trend in exposed populations using meteorological data from monitoring stations as well as climate models. We further analyzed this data to better characterize seasonal, regional, and temporal trends.

\section{Materials and Methods}

\subsection{Population Data}

We acquired information on the 150 most populated metropolitan locations of the world with populations over 3 million from the World Atlas [48] and downloaded their boundaries from Open Street Map [49] using python software (python 2.7.1). We obtained metropolitan human population data for these cities from the United Nations Human Population Division (UNPD) [50]. We then used a simple linear interpolation method to estimate yearly populations as described previously [51]. We divided the 150 global cities into four zones: North Temperate (latitude between $23.5^{\circ} \mathrm{N}$ and $66.5^{\circ} \mathrm{N}$ ); North Tropic $\left(0^{\circ} \mathrm{N}\right.$ and $\left.23.5^{\circ} \mathrm{N}\right)$; South Temperate (23.5 $\mathrm{S}$ and $\left.66.5^{\circ} \mathrm{S}\right)$; South Tropic ( $0 \mathrm{~S}$ and $\left.23.5^{\circ} \mathrm{S}\right)$. We also grouped these global cities according to the World Health Organization (WHO) classification system into [52]: African Region; Region of the Americas; South East Asia Region; European Region; Eastern Mediterranean Region; and Western Pacific Region.

\subsection{EHE and EPE Metrics}

We obtained daily maximum temperature (TMAX) and precipitation data for 1980-2017 from the Global Historical Climatology Network (GHCN) through the National Climate Data Center (NCDC) data portal (https: / / www.ncdc.noaa.gov). If a metropolitan location had multiple meteorological stations, we used the one closest to the urban core. If no station data were available, we borrowed information from stations that were located within a $50 \mathrm{~km}$ radius of the location boundary or set it to "missing" if no stations were available within the $50 \mathrm{~km}$ radius. We used 20 years (01/1980-12/1999) of daily meteorological data (maximum temperature, precipitation) as the base period to calculate calendar day and location-specific 95th percentile thresholds to define EHE and EPE. For example, the baseline data for Beijing for January 16th consisted of all daily observations for Beijing from 1 January to 31 January from 1980 to 1999. If a metropolitan area had more than $30 \%$ of daily observations missing during the baseline period (1980-1999), we dropped them from the analysis. Based on the distribution of this data, we identified location and calendar day specific 95th percentile threshold values for TMAX and precipitation, referred to as $\mathrm{EHE}_{95}$, and $\mathrm{EPE}_{95}$ thresholds, respectively. Calendar day-specific TMAX and precipitation values for each metropolitan region were compared with their respective $\mathrm{EHE}_{95}$ and $\mathrm{EPE}_{95}$ thresholds and assigned a value of "1" if they exceeded the threshold, and " 0 " otherwise $[18,53]$. Days where TMAX exceeded EHE 95 were identified as extreme 
heat events, and days where the daily total precipitation exceeded the $\mathrm{EPE}_{95}$ thresholds were identified as extreme precipitation events.

Since numerous cities did not have weather station data satisfying our inclusion criteria, we also performed additional analysis using ECMWF ERA5 reanalysis products with $0.25 \times 0.25$ degree spatial resolution [54]. We used the hourly ECMWF ERA5 products to calculate daily TMAX and total precipitation. Based on these data, we calculated EHE and EPE for all 150 cities using the aforementioned method (Figure 1, Supplementary Table S1).

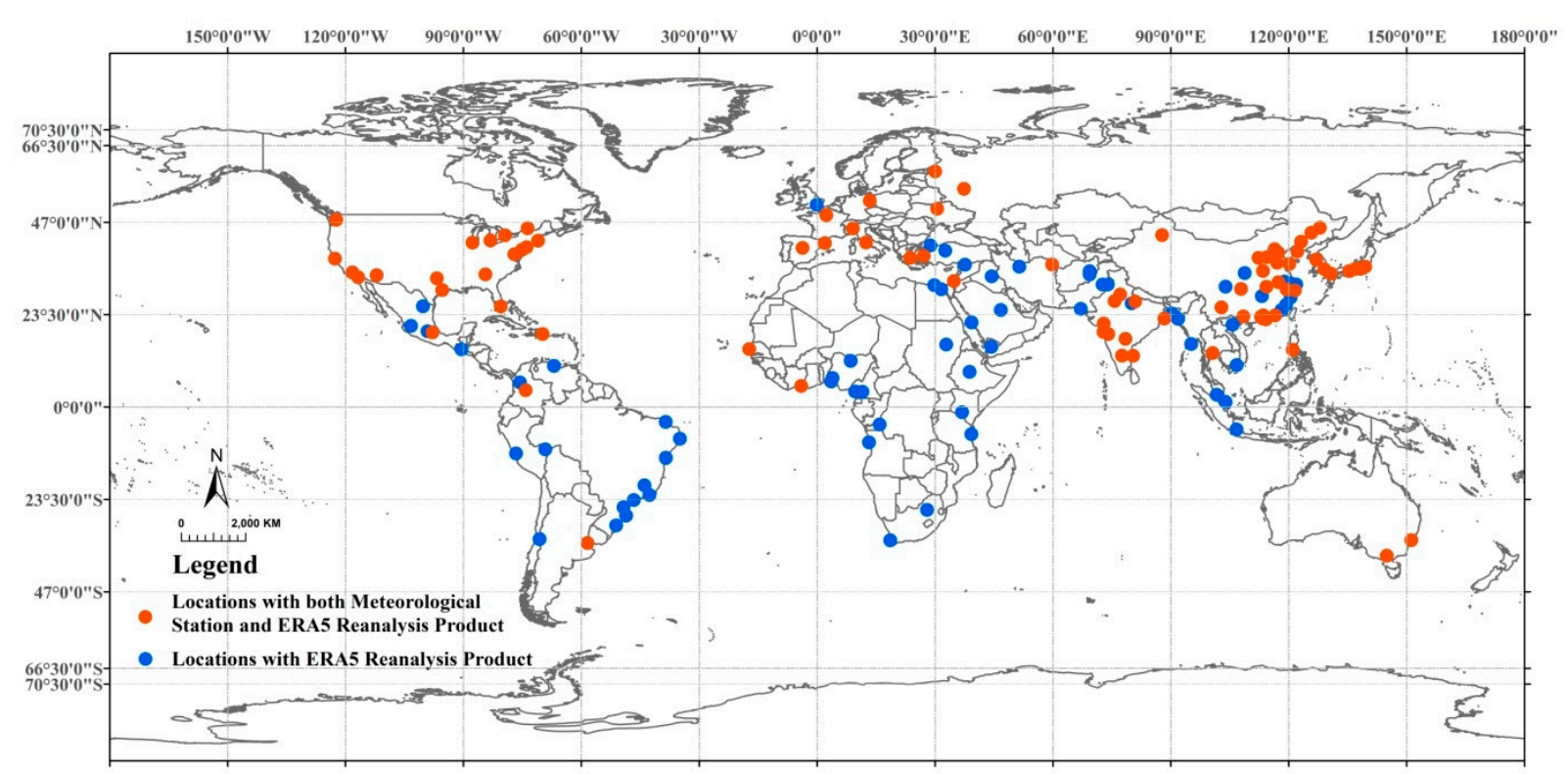

Figure 1. Global distribution of the 150 most populated metropolitan locations.

To harmonize the definition of season between the Northern and Southern Hemisphere, we defined June, July and August as summer in the Northern Hemisphere and winter in the Southern Hemisphere. Likewise, December, January and February were classified as winter in the Northern hemisphere and summer in the Southern Hemisphere. Spring (March, April, and May) and fall (September, October, and November) definitions followed suit. We calculated seasonal and yearly sums of EHE and EPE for all metropolitan locations. We computed yearly exposed populations for each city based on the yearly population and frequency of EHE and EPE for the respective cities (Supplementary Equation S1). We also characterized EHE and EPE frequency distribution across seasons (Spring, Summer, Fall, Winter), by latitudes (North Temperate, North Tropic, South Temperate, South Tropic), and the WHO regions (Africa, Eastern Mediterranean, Europe, Region of the Americas, South East Asia, and Western Pacific Region). Finally, we applied ordinary least squares (OLS) regression to estimate seasonal increases in rates of EHE and EPE frequency across these regions and time periods.

\section{Results}

Of the 150 largest cities, 84 had valid weather data during the 1980-2017 period that satisfied our inclusion criteria. On average, these 84 cities were missing less than $8 \%$ of daily observations (Supplementary Table S1). For the analysis involving ECMWF ERA5 reanalysis products, we used all 150 metropolitan locations. As depicted in Figure 2, there was a clear increasing trend in frequencies of EHE and EPE across the major city centers of the world during the last four decades (1980-2017). These increases, combined with the steady growth in urban populations in these 150 locations translated into a $500 \%$ increase in the number of urban populations exposed to EHE and EPE during the four decades. When this analysis was repeated using ECMWF ERA5 reanalysis products, the percent 
increase in urban populations exposed to EHE was similar, however this was not the case for populations exposed to EPE ( $150 \%$ increase, Supplementary Figure S1).

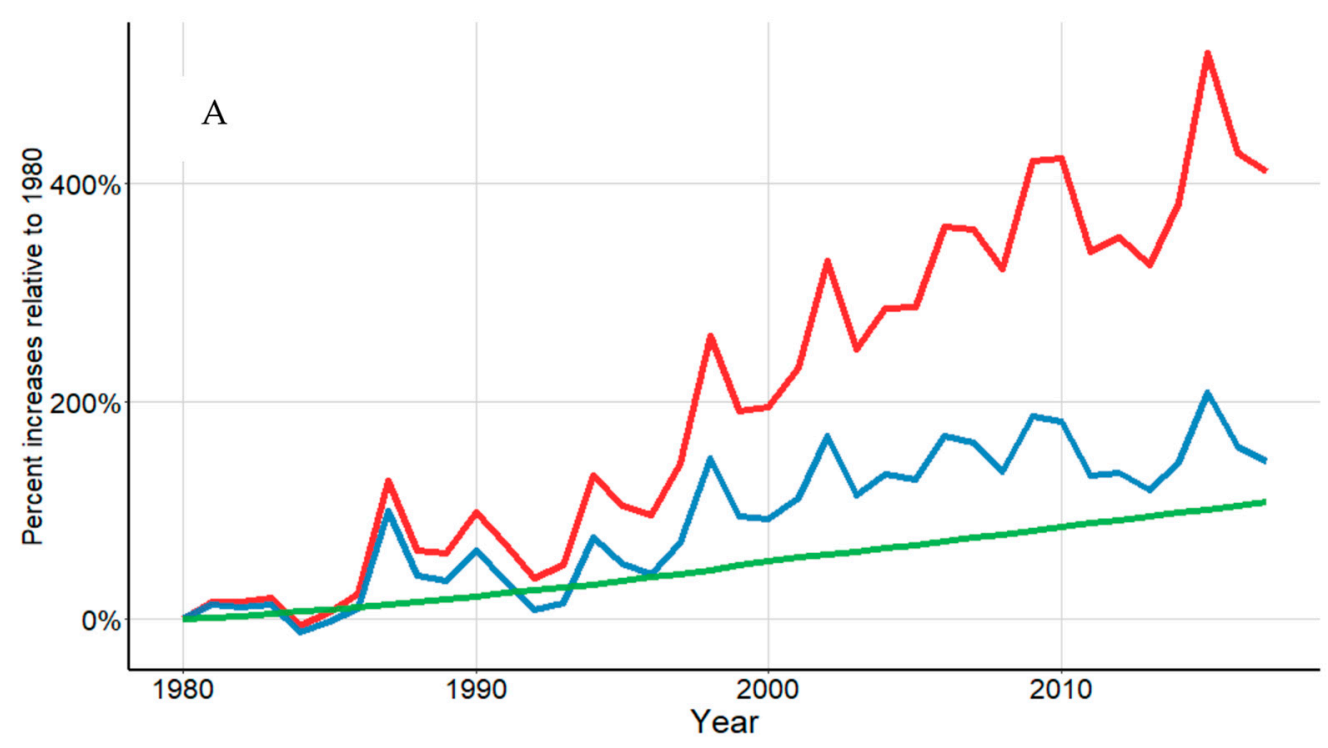

- Exposed Population - Extreme Precipitation Events - Population

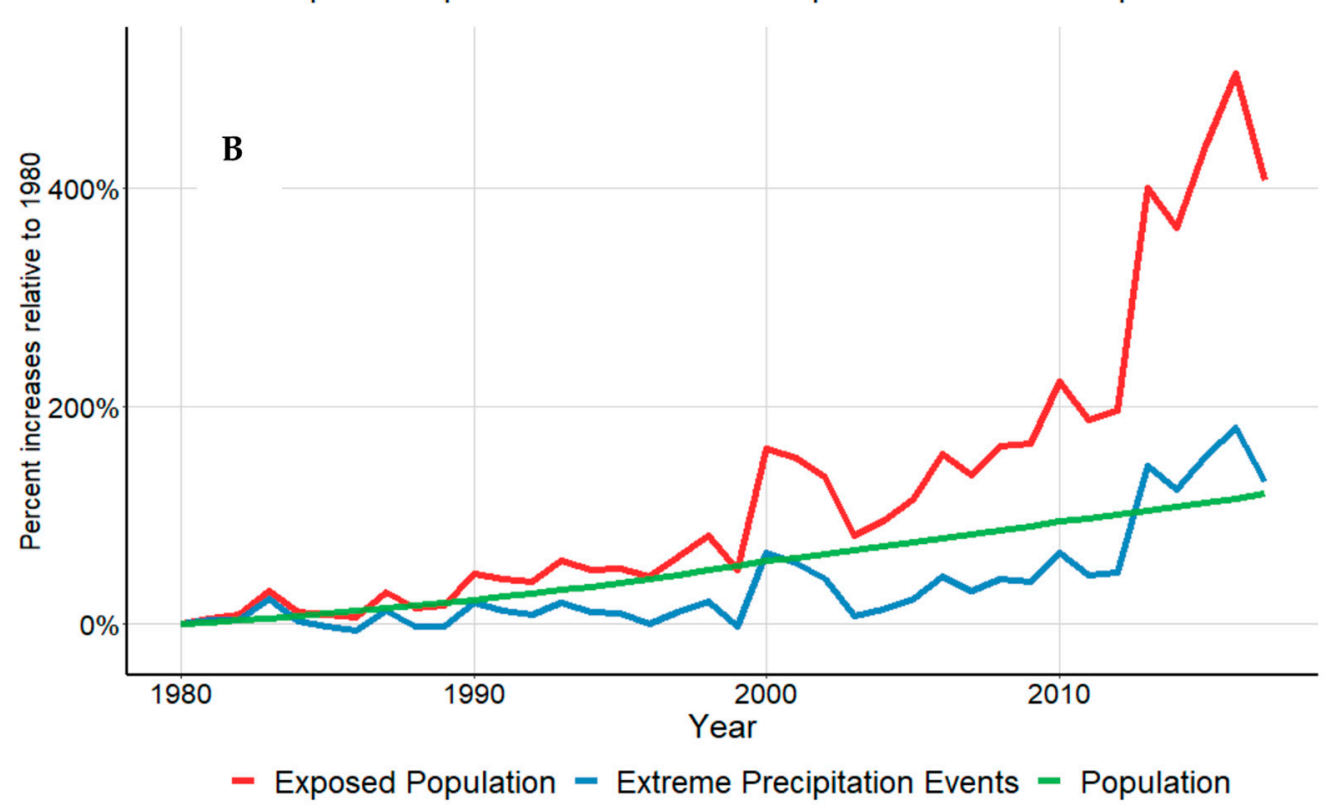

Figure 2. Changes in EHE (A) and EPE (B) exposed populations during the last four decades.

As depicted in Figure 3 and Supplementary Table S2, metropolitan locations in the African Region had the highest EHE frequency during the 2000s (median seasonal EHE (IQR): 10.5 (6.3-19.7), 9.3 (3.3-16.2), 12.3 (4.3-15.0), and 10.8 (6.0-16.6) for spring, summer, fall, and winter, respectively), while the Eastern Mediterranean Region had the highest EHE frequency during the 2010s (median seasonal EHE (IQR): 7.2 (5.1-12.4), 11.8 (8.1-18.9), (15.5 (10.6-20.4), and 4.9 (3.1-9.9), for spring, summer, fall, and winter, respectively). Likewise, metropolitan locations in the Western Pacific Region had the most pronounced increases in EPE during the 2010s (median seasonal EPE (IQR) (9.1 (5.0-18.7), 7.8 (4.0-13.9), 6.8 (4.0-10.2), 8.0 (5.0-16.5), for spring, summer, fall, and winter, respectively (Figure 2, Supplementary Table S2). When we repeated this analysis using ECMWF ERA5 reanalysis products, findings for EHE did not change, while the trends for EPE were no longer pronounced ( Supplementary Figure S2b). 

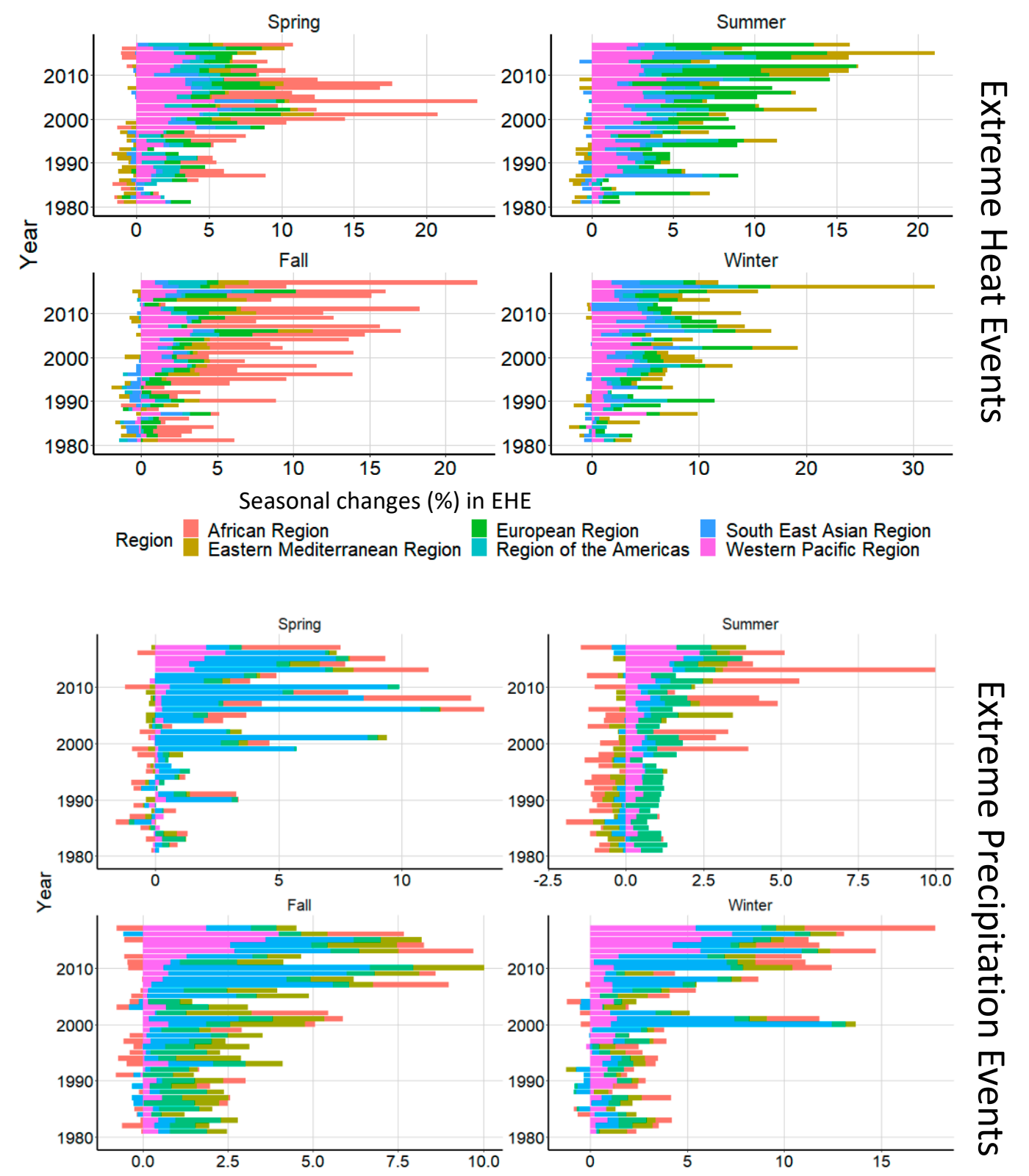

Region African Region European Region Region of the Americas $\quad$ South East Asian Region western Pacific Region

Figure 3. Seasonal changes in EHE (top) and EPE (bottom) during 1980-2017.

Based on regression analysis, we identified the top 10 metropolitan locations with the highest seasonal rate of increases in EHE and EPE frequencies (Figure 4). Six out of the top ten cities with the highest seasonal increases in EHE frequency during spring and summer are from North Temperate zones, while eight out of the top ten cities with the highest rate of increasing EHE frequency in fall and winter are from North Tropic zones (Figure 4A). In contrast, the majority of cities with the highest rate of increases in EPE were from North Temperate zones, irrespective of the season (Figure 4B). 


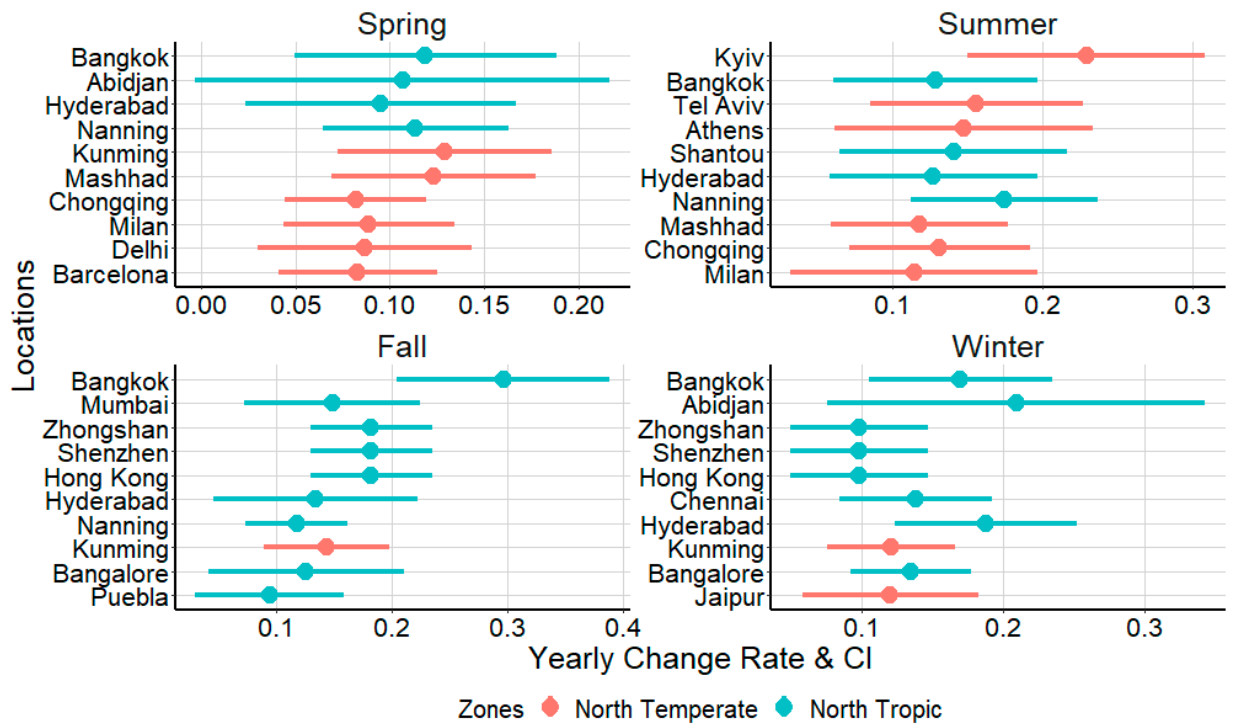

(A) Seasonal Increases in EHE

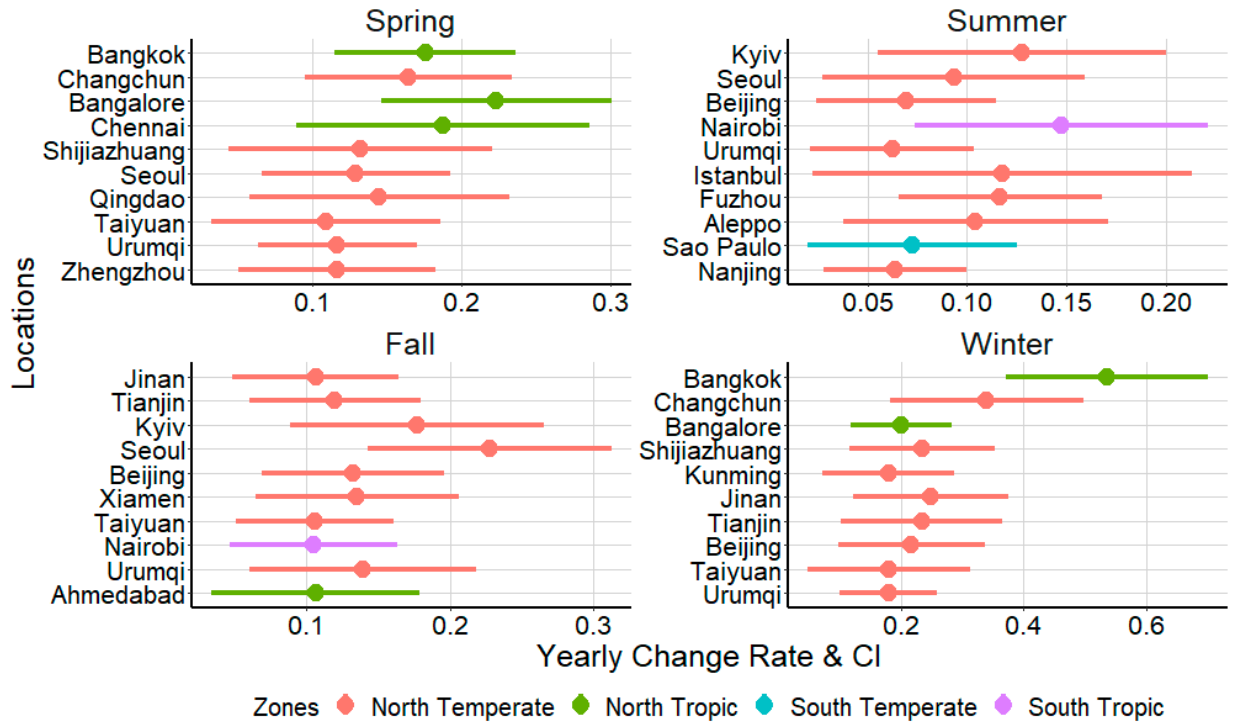

(B) Seasonal Increases in EPE

Figure 4. Ten metropolitan locations with the highest rate of seasonal increases in EHE (top) and EPE (bottom).

When we considered cities individually, Bangkok had the fastest rate of seasonal increases in EHE during fall (0.297 EHE/Fall; 95\%CI: 0.204-0.389), while Kyiv had the fastest rate of EHE increases during summer (0.229, 95\%CI: 0.150-0.308). Likewise, Abidjan had the fastest rate of EHE increases during winter (0.209, 95\%CI: 0.071-0.343), while the rates of increase were highest in Kunming during spring (0.119, 95\%CI: 0.069-0.177). Overall, we observed higher rates of EHE increases during the summer and fall seasons. Cities such as Hyderabad and Bangkok experienced EHE increases across all seasons while the rate of EHE increases for other locations were confined to only one or two seasons (Figure 4A). For EPE, the highest wintertime increase was observed in Bangkok (0.535 EHEs/winter, 95\%CI: 0.371-0.699), and Seoul during fall (0.228, 95\%CI: 0.143-0.313). Likewise, the rate of EPE increases was highest in Bangalore during spring $(0.224,95 \% \mathrm{CI}$ : $0.146-0.301)$ and in Nairobi during summer $(0.148,95 \%$ CI: 0.074-0.221). The rate of EPE increases were more pronounced during winter, with cities such as Urumqi experiencing increases during all seasons while cities such as Taiyuan, Seoul and Beijing experiencing increases during three out of four seasons (Figure 4B). 
We also explored the relationship between EHE/EPE calculated using weather station data vs. ERA5 reanalysis products (Figure 5). Overall, the agreement in EHE frequency between monitoring stations and ERA5 was highest during fall $(\mathrm{r}=0.55)$ and lowest during spring $(r=0.28)$ (Figure 5A). Overall, the ERA5 based estimates tend to underestimate the actual frequency of EHE. Similarly, correlation of EPE frequency derived using monitoring station data and ERA5 reanalysis products were highest during spring $(r=0.38)$ and lowest during summer $(r=0.12)$ (Figure $5 B)$. Overall, the agreement between monitoring stations and ERA5 based estimates were higher for EHE and lower for EPE.
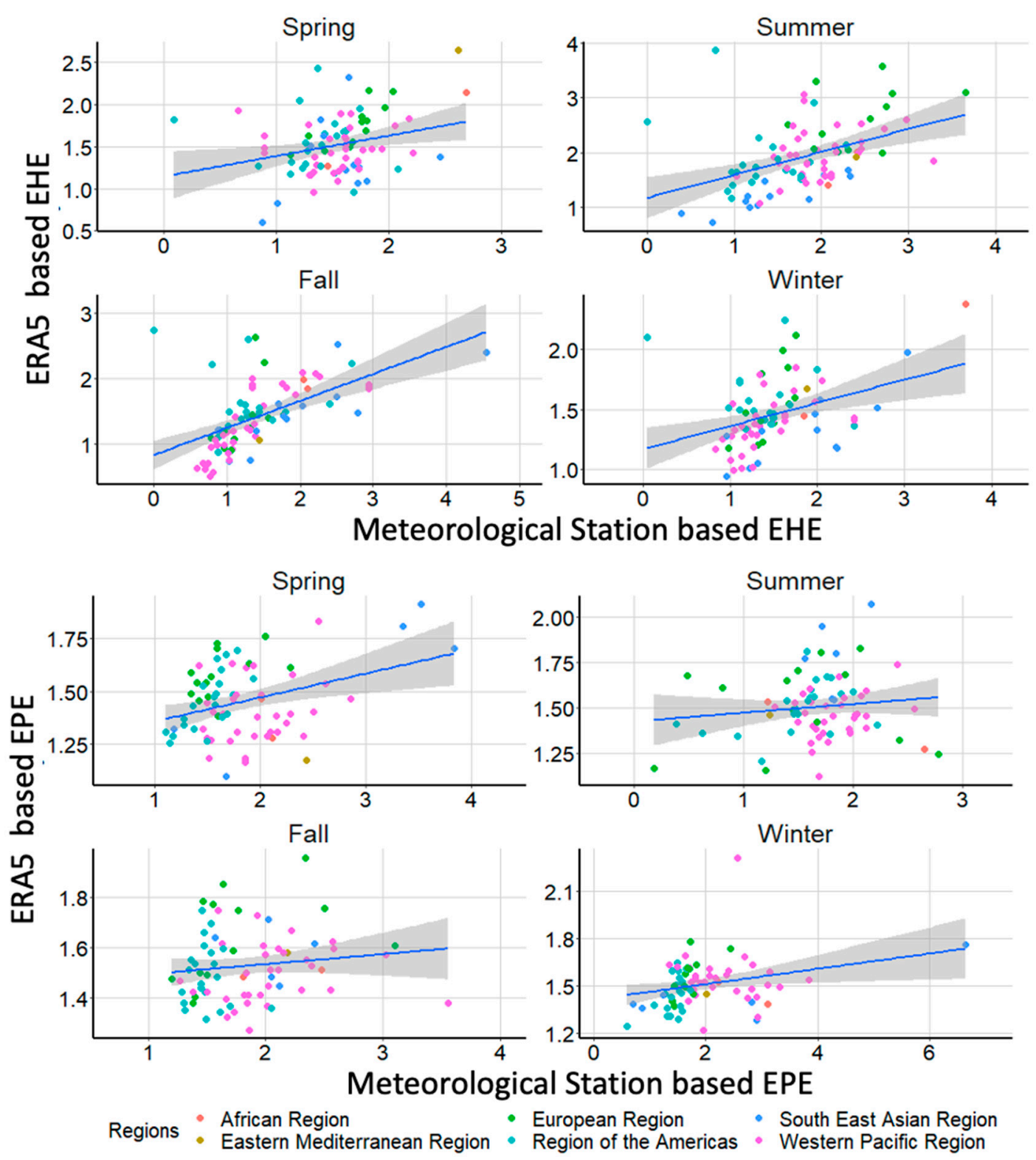

Figure 5. Correlation between weather station vs. ERA5 based EHE (A) top and EPE (B) bottom frequencies during 1980-2017.

\section{Discussion}

While the list of adverse human health impacts that are tied to the ongoing climate change continues to grow, the geographic distribution of populations that are exposed to extreme events and therefore, at risk of experiencing adverse health outcomes are lacking at a global scale. Taking into consideration both the rapid rise in urban populations and the disproportionate increases in EHE and EPE in major cities [30,31], we show that the 
number of individuals exposed to extreme events has increased by $500 \%$ in these global population centers since the 1980s. Our findings are of particular concern given that the most recent United Nations projections suggest that urban populations will continue to grow over the next decades, with the current share of urban populations increasing from $55 \%$ to $68 \%$ by 2050 [35]. Importantly, close to $90 \%$ of the projected 2.5 billion increase in urban populations will take place in Asia and Africa [55]. Our findings suggest that there is a pressing need to enhance adaptation strategies in these areas to deal with increases in populations exposed to extreme heat and precipitation events.

Our data showing increases in EPE across cities in the Western Pacific Region during the 2010s is consistent with Huang et al. [56], who tied special circulation patterns favorable to wintertime extreme precipitation events over South China in the 2010s. The large number of cities from the European Region and Western Pacific Region with noted increases in summertime EHE is consistent with recent studies focusing on these regions [57,58], as well as the noted increases in European summer heatwaves [59].

When we compared EHE results that were derived using weather station data to those derived using ERA5 reanalysis products, the agreement was considerably better for EHE compared to EPE. This is expected since simulating precipitation is generally much more challenging for models than simulating temperature [60]. Although the weather stationbased calculation of exposed populations was based on 84 cities while the ERA5 reanalysisbased calculation included all 150 cities, we observed remarkable consistencies in relative increases in populations exposed to EHE between 1980 and 2017 ( $500 \%)$. However, there was a significant difference in populations exposed to EPE when comparing the stationbased measures as opposed to the ERA5 based measures (500\% vs. 150\%). Although, the ERA5 based estimates included 66 additional cities that did not have weather stationbased estimates, it is unlikely that they all experienced reduced frequency of EPE. This suggest that ERA5 products underestimate precipitation considerably in these metropolitan locations. Focusing on specific regions, there was a better agreement between the reanalysis product and weather station based EHE for the European region, likely due to good spatial and temporal coverage of the station-based data. The Region of the Americas included both North and South America, which likely resulted in the lower agreement, although North America has a good spatial and temporal coverage of weather stations. Due to the relatively small number of stations over the African and Eastern Mediterranean, it was difficult to draw a meaningful conclusion comparing the two different approaches. Moreover, the WHO classification of the world region is not based on climatological regions, which further complicates the interpretation. These findings highlight the caveats of using exposure metrics that are derived solely based on modeled data in epidemiological studies.

There are several strengths of our study. This study focused on potential exposures to extreme heat and precipitation events in the 150 major cities of the world over the past four decades. We further analyzed how these exposures varied across WHO regions and latitudes, which provided valuable information for assessing regional disparities in exposure and potential health impacts. Our findings will inform public health preparedness, particularly across low- and middle-income countries where such data have been lacking. Our study has some limitations as well. First, only 84 out of the 150 cities had weather station level data that matched our selection criteria, which limited our analysis. To overcome this, we used ERA5 reanalysis products. However, limited agreement between ERA5 reanalysis products and weather station level extreme event data, particularly with regards to EPE, raises concerns about just relying on the ERA5 based analysis alone. Nevertheless, these findings also underscore the need for sustained monitoring stations to capture the expected continuation of increases in weather extremes in a warming world.

Given the linkage between exposure to extreme events and impaired health [1-3], our data showing rapid increases in urban population exposed to EHE and EPE underscores the need for community specific adaptation strategies. Since vulnerabilities to extreme weather events depend upon range of characteristics, such as sociodemographic factors including race, ethnicity, income, pre-existing health conditions, access to medical care, 
as well as capacity to adapt to these new set of hazards, municipalities across the globe need to invest in early warning systems. Given that currently available weather-based warnings with a week to ten-day lead time does not provide enough time to mobilize public health responses, these new set of early warnings should strive for seasonal to subseasonal lead time and should take into considerations location specific geographic and sociodemographic drivers of vulnerability, as well as spatial heterogeneity in exposures.

\section{Conclusions}

The confluence of disproportionate increases in the frequency of extreme weather events in city centers, and rapid rises in urban populations has turned major cities across the globe into flashpoints for climate change driven disease burden with a $500 \%$ increase in populations exposed to extreme heat and precipitation events over the past four decades. The projected increases in the frequency of extreme heat events and the continued rises in urban populations combined with ever increasing disparities in income, food, and healthcare access in urban areas will only worsen public health outcomes in these city centers in coming decades. Cities across the globe need to prepare for such increases in exposed populations and begin evaluating the efficacy of their adaptation strategies.

Supplementary Materials: The following are available online at https:/ /www.mdpi.com/1660-460 1/18/3/1293/s1, Table S1: Details of 150 most populated included in the study. Table S2: Summary of frequency of EHE and EPE by Season, Decade and WHO Regions. Figure S1. Change of EHE (top) and EPE (bottom) exposed population in the last four decades using based on data from ERA5 reanalysis. FigureS2: Metropolitan locations with fastest increasing trend in EHE (top) and EPE (bottom) based on ERA5 reanalysis data.

Author Contributions: Study design: A.S., R.M., X.-Z.L., C.J.; data compilation: L.L., C.J.; data analysis: L.L., C.J.; drafting manuscript: L.L., C.J., R.M., X.-Z.L., A.S. All authors have read and agreed to the published version of the manuscript.

Funding: L.L. was supported through the Chinese Scholarship Council and Wuhan University PhD Short-time Mobility Program. A.S., R.M., and X.-Z.L. received funding from NSF and NOAA through Belmont Forum (Award Number (FAIN): 2025470).

Institutional Review Board Statement: Not Applicable.

Informed Consent Statement: Not Applicable.

Data Availability Statement: The data used for this study is publicly available for everyone.

Conflicts of Interest: The authors declare no conflict of interest.

\section{References}

1. Stocker, T.F.; Qin, D.; Plattner, G.K.; Tignor, M.; Allen, S.K.; Boschung, J.; Nauels, A.; Xia, Y.; Bex, V.; Midgley, P.M. Summary for Policymakers. In Climate Change 2013: The Physical Science Basis; Contribution of Working Group I to the Fifth Assessment Report of the Intergovernmental Panel on Climate Change; IPCC: Geneva, Switzerland, 2013.

2. USGCRP. Impacts, Risks, and Adaptation in the United States: Fourth National Climate Assessment, Volume II; U.S. Global Change Research Program: Washington, DC, USA, 2018; p. 1515.

3. WHO. Quantitative Risk Assessment of the Effects of Climate Change on Selected Causes of Death, 2030s and 2050s; WHO: Geneva, Switzerland, 2014.

4. Madrigano, J.; Ito, K.; Johnson, S.; Kinney, P.L.; Matte, T. A Case-Only Study of Vulnerability to Heat Wave-Related Mortality in New York City (2000-2011). Environ. Health Perspect. 2015, 123, 672-678. [CrossRef] [PubMed]

5. Remigio, R.V.; Jiang, C.; Raimann, J.; Kotanko, P.; Usvyat, L.; Maddux, F.W.; Kinney, P.; Sapkota, A. Association of Extreme Heat Events With Hospital Admission or Mortality Among Patients With End-Stage Renal Disease. JAMA Netw. Open 2019, 2, e198904. [CrossRef] [PubMed]

6. Coffel, E.D.; Horton, R.M.; de Sherbinin, A. Temperature and humidity based projections of a rapid rise in global heat stress exposure during the 21st century. Environ. Res. Lett. 2018, 13. [CrossRef] [PubMed]

7. Anderson, G.B.; Bell, M.L. Heat waves in the United States: Mortality risk during heat waves and effect modification by heat wave characteristics in 43 U.S. communities. Environ. Health Perspect. 2011, 119, 210-218. [CrossRef] [PubMed] 
8. Armstrong, B.; Sera, F.; Vicedo-Cabrera, A.M.; Abrutzky, R.; Åström, D.O.; Bell, M.L.; Chen, B.Y.; de Sousa Zanotti Stagliorio Coelho, M.; Correa, P.M.; Dang, T.N.; et al. The Role of Humidity in Associations of High Temperature with Mortality: A Multicountry, Multicity Study. Environ. Health Perspect. 2019, 127, 97007. [CrossRef]

9. Bayram, H.; Bauer, A.K.; Abdalati, W.; Carlsten, C.; Pinkerton, K.E.; Thurston, G.D.; Balmes, J.R.; Takaro, T.K. Environment, Global Climate Change, and Cardiopulmonary Health. Am. J. Respir. Crit. Care Med. 2017, 195, 718-724. [CrossRef]

10. Lin, S.; Luo, M.; Walker, R.J.; Liu, X.; Hwang, S.A.; Chinery, R. Extreme high temperatures and hospital admissions for respiratory and cardiovascular diseases. Epidemiology 2009, 20, 738-746. [CrossRef]

11. Bobb, J.F.; Obermeyer, Z.; Wang, Y.; Dominici, F. Cause-specific risk of hospital admission related to extreme heat in older adults. Jama 2014, 312, 2659-2667. [CrossRef]

12. Wang, Y.; Bobb, J.F.; Papi, B.; Wang, Y.; Kosheleva, A.; Di, Q.; Schwartz, J.D.; Dominici, F. Heat stroke admissions during heat waves in 1,916 US counties for the period from 1999 to 2010 and their effect modifiers. Environ. Health 2016, 15, 83. [CrossRef]

13. Soneja, S.; Jiang, C.; Fisher, J.; Upperman, C.R.; Mitchell, C.; Sapkota, A. Exposure to extreme heat and precipitation events associated with increased risk of hospitalization for asthma in Maryland, U.S.A. Environ. Health 2016, 15, 57. [CrossRef]

14. Leclerc, H.; Schwartzbrod, L.; Dei-Cas, E. Microbial agents associated with waterborne diseases. Crit. Rev. Microbiol. 2002, 28, 371-409. [CrossRef] [PubMed]

15. Kunkel, K.E. North American Trends in Extreme Precipitation. Natural Hazards 2003, 29, 291-305. [CrossRef]

16. Lin, S.; Sun, M.; Fitzgerald, E.; Hwang, S.A. Did summer weather factors affect gastrointestinal infection hospitalizations in New York State? Sci. Total Environ. 2016, 550, 38-44. [CrossRef] [PubMed]

17. Wang, P.; Goggins, W.B.; Chan, E.Y.Y. A time-series study of the association of rainfall, relative humidity and ambient temperature with hospitalizations for rotavirus and norovirus infection among children in Hong Kong. Sci. Total Environ. 2018, 643, 414-422. [CrossRef] [PubMed]

18. Jiang, C.; Shaw, K.S.; Upperman, C.R.; Blythe, D.; Mitchell, C.; Murtugudde, R.; Sapkota, A.R.; Sapkota, A. Climate change, extreme events and increased risk of salmonellosis in Maryland, USA: Evidence for coastal vulnerability. Environ. Int. 2015, 83, 58-62. [CrossRef]

19. Lemaitre, J.; Pasetto, D.; Perez-Saez, J.; Sciarra, C.; Wamala, J.F.; Rinaldo, A. Rainfall as a driver of epidemic cholera: Comparative model assessments of the effect of intra-seasonal precipitation events. Acta Trop 2019, 190, 235-243. [CrossRef]

20. Ngwa, M.C.; Liang, S.; Kracalik, I.T.; Morris, L.; Blackburn, J.K.; Mbam, L.M.; Ba Pouth, S.F.; Teboh, A.; Yang, Y.; Arabi, M.; et al. Cholera in Cameroon, 2000-2012: Spatial and Temporal Analysis at the Operational (Health District) and Sub Climate Levels. PLoS Negl. Trop Dis. 2016, 10, e0005105. [CrossRef]

21. Pecl, G.T.; Araujo, M.B.; Bell, J.D.; Blanchard, J.; Bonebrake, T.C.; Chen, I.C.; Clark, T.D.; Colwell, R.K.; Danielsen, F.; Evengard, B.; et al. Biodiversity redistribution under climate change: Impacts on ecosystems and human well-being. Science 2017, 355. [CrossRef]

22. Doney, S.C.; Ruckelshaus, M.; Duffy, J.E.; Barry, J.P.; Chan, F.; English, C.A.; Galindo, H.M.; Grebmeier, J.M.; Hollowed, A.B.; Knowlton, N.; et al. Climate change impacts on marine ecosystems. Ann. Rev. Mar. Sci. 2012, 4, 11-37. [CrossRef]

23. Lindner, M.; Maroschek, M.; Netherer, S.; Kremer, A.; Barbati, A.; Garcia-Gonzalo, J.; Seidl, R.; Delzon, S.; Corona, P.; Kolström, M.; et al. Climate change impacts, adaptive capacity, and vulnerability of European forest ecosystems. Forest Ecol. Manag. 2010, 259, 698-709. [CrossRef]

24. Wheeler, T.; von Braun, J. Climate Change Impacts on Global Food Security. Science 2013, 341, 508-513. [CrossRef] [PubMed]

25. Koken, P.J.; Piver, W.T.; Ye, F.; Elixhauser, A.; Olsen, L.M.; Portier, C.J. Temperature, air pollution, and hospitalization for cardiovascular diseases among elderly people in Denver. Environ. Health Perspect. 2003, 111, 1312-1317. [CrossRef] [PubMed]

26. Bou-Zeid, E.; Li, D. Synergistic Interactions between Urban Heat Islands and Heat Waves: The Impact in Cities Is Larger than the Sum of Its Parts*. J. Appl. Meteorol. Climatol. 2013, 52, 2051-2064. [CrossRef]

27. Khomenko, S.; Cirach, M.; Pereira-Barboza, E.; Mueller, N.; Barrera-Gómez, J.; Rojas-Rueda, D.; de Hoogh, K.; Hoek, G.; Nieuwenhuijsen, M. Premature mortality due to air pollution in European cities: A health impact assessment. Lancet Planet Health 2021. [CrossRef]

28. Petkova, E.P.; Vink, J.K.; Horton, R.M.; Gasparrini, A.; Bader, D.A.; Francis, J.D.; Kinney, P.L. Towards More Comprehensive Projections of Urban Heat-Related Mortality: Estimates for New York City under Multiple Population, Adaptation, and Climate Scenarios. Environ. Health Perspect. 2017, 125, 47-55. [CrossRef]

29. Anderson, B.G.; Bell, M.L. Weather-related mortality: How heat, cold, and heat waves affect mortality in the United States. Epidemiology (Camb. MA) 2009, 20, 205-213. [CrossRef]

30. Zhang, W.; Villarini, G.; Vecchi, G.A.; Smith, J.A. Urbanization exacerbated the rainfall and flooding caused by hurricane Harvey in Houston. Nature 2018, 563, 384-388. [CrossRef]

31. Singh, J.; Karmakar, S.; PaiMazumder, D.; Ghosh, S.; Niyogi, D. Urbanization alters rainfall extremes over the contiguous United States. Environ. Res. Lett. 2020, 15. [CrossRef]

32. Tan, J.; Zheng, Y.; Tang, X.; Guo, C.; Li, L.; Song, G.; Zhen, X.; Yuan, D.; Kalkstein, A.J.; Li, F. The urban heat island and its impact on heat waves and human health in Shanghai. Int. J. Biometeorol. 2010, 54, 75-84. [CrossRef]

33. Pullen, J.; Orton, P.M.; Meir, T.; Holt, T.; Thompson, W.T.; Arend, M.F. Forecasting the New York City Urban Heat Island and Sea Breeze during Extreme Heat Events. Weather Forecast 2013, 28, 1460-1477. [CrossRef] 
34. Peng, S.; Piao, S.; Ciais, P.; Friedlingstein, P.; Ottle, C.; Bréon, F.M.; Nan, H.; Zhou, L.; Myneni, R.B. Surface urban heat island across 419 global big cities. Environ. Sci. Technol. 2012, 46, 696-703. [CrossRef] [PubMed]

35. Nations, U. World Urbanization Prospects: The 2018 Revision; United Nations: New York, NY, USA, 2019; pp. 1-126.

36. Madlener, R.; Sunak, Y. Impacts of urbanization on urban structures and energy demand: What can we learn for urban energy planning and urbanization management? Sustain. Cities Soc. 2011, 1, 45-53. [CrossRef]

37. Zhao, P. Sustainable urban expansion and transportation in a growing megacity: Consequences of urban sprawl for mobility on the urban fringe of Beijing. Habitat Int. 2010, 34, 236-243. [CrossRef]

38. Roy, D.; Sarker Dev, D.; Sheheli, S. Food Security in Bangladesh: Insight from Available Literature. J. Nutr. Food Secur. 2019, 4, 66-75. [CrossRef]

39. Abedi, V.; Olulana, O.; Avula, V.; Chaudhary, D.; Khan, A.; Shahjouei, S.; Li, J.; Zand, R. Racial, Economic and Health Inequality and COVID-19 Infection in the United States. medRxiv 2020, 1-11. [CrossRef]

40. Adebayo, A.M.; Obembe, T.A.; Adebayo, B.E. Morbidity Pattern and Choice of Care in an Urban Slum of a Metropolitan State, Southwestern Nigeria. West Afr. J. Med. 2020, 37, 268-274.

41. Brown, D.R.; Brewster, L.G. The food environment is a complex social network. Soc. Sci. Med. 2015, 133, 202-204. [CrossRef]

42. Michimi, A.; Wimberly, M.C. The food environment and adult obesity in US metropolitan areas. Geospat. Health 2015, 10, 368. [CrossRef]

43. Sanders, S.R.; Cope, M.R.; Park, P.N.; Jeffery, W.; Jackson, J.E. Infants without health insurance: Racial/ethnic and rural/urban disparities in infant households' insurance coverage. PLoS ONE 2020, 15, e0222387. [CrossRef]

44. Krämer, A.; Khan, M.; Jahn, H. Public Health in Megacities and Urban Areas: A Conceptual Framework. In Health in Megacities and Urban Areas; Springer-Verlag: Berlin/Heidelberg, Germany, 2011; pp. 3-20. [CrossRef]

45. Green, H.; Bailey, J.; Schwarz, L.; Vanos, J.; Ebi, K.; Benmarhnia, T. Impact of heat on mortality and morbidity in low and middle income countries: A review of the epidemiological evidence and considerations for future research. Environ. Res. 2019, 171, 80-91. [CrossRef]

46. Campbell, S.; Remenyi, T.A.; White, C.J.; Johnston, F.H. Heatwave and health impact research: A global review. Health Place 2018, 53, 210-218. [CrossRef] [PubMed]

47. Butler, C.D.; Hanigan, I.C. Anthropogenic climate change and health in the Global South. Int. J. Tuberc. Lung Dis. 2019, 23, 1243-1252. [CrossRef] [PubMed]

48. Worldatlas. Available online: https:/ / www.worldatlas.com (accessed on 15 May 2020).

49. Map, O.S. Open Street Map. Available online: https:/ / www.openstreetmap.org (accessed on 15 May 2020).

50. United Nations Population Division (UNPD). Available online: https://www.un.org/development/desa/pd/ (accessed on 1 February 2021).

51. WHO; UNICEF; UNFPA; World Bank Group; The United Nations Population Division. Trends in Maternal Mortality: 1990 to 2015. Estimates by WHO, UNICEF, UNFPA, World Bank Group and the United Nations Population Division; World Health Organization: Geneva, Switzerland, 2015; pp. 1-96.

52. WHO. World Health Organization. Available online: https://www.who.int/chp/about/regions/en/ (accessed on 1 February 2021).

53. Romeo Upperman, C.; Parker, J.; Jiang, C.; He, X.; Murtugudde, R.; Sapkota, A. Frequency of Extreme Heat Event as a Surrogate Exposure Metric for Examining the Human Health Effects of Climate Change. PLoS ONE 2015, 10, e0144202. [CrossRef] [PubMed]

54. ECMWF. ERA5. Available online: https://www.ecmwf.int/en/forecasts/datasets/reanalysis-datasets/era5 (accessed on 1 August 2019).

55. Ritchie, H. Urbanization. Our World in Data. 2018. Available online: https://ourworldindata.org/urbanization (accessed on 1 February 2021).

56. Huang, W.; Yang, Z.; He, X.; Lin, D.; Wang, B.; Wright, J.S.; Chen, R.; Ma, W.; Li, F. A possible mechanism for the occurrence of wintertime extreme precipitation events over South China. Clim. Dyn. 2018, 52, 2367-2384. [CrossRef]

57. Sun, Y.; Zhang, X.; Zwiers, F.W.; Song, L.; Wan, H.; Hu, T.; Yin, H.; Ren, G. Rapid increase in the risk of extreme summer heat in Eastern China. Nat. Clim. Chang. 2014, 4, 1082-1085. [CrossRef]

58. Hsu, P.-C.; Qian, Y.; Liu, Y.; Murakami, H.; Gao, Y. Role of Abnormally Enhanced MJO over the Western Pacific in the Formation and Subseasonal Predictability of the Record-Breaking Northeast Asian Heatwave in the Summer of 2018. J. Clim. 2020, 33, 3333-3349. [CrossRef]

59. Fink, A.H.; Bruecher, T.; Krueger, A.; Leckebusch, G.C.; Pinto, J.G.; Ulbrich, U. The 2003 European summer heatwaves and drought synoptic diagnosis and impacts. Weather 2004, 59, 209-216. [CrossRef]

60. Woldemeskel, F.M.; Sharma, A.; Sivakumar, B.; Mehrotra, R. Quantification of precipitation and temperature uncertainties simulated by CMIP3 and CMIP5 models. J. Geophys. Res. Atmos. 2016, 121, 3-17. [CrossRef] 